\title{
Transplacental transfer of cefuroxime in uncomplicated pregnancies and those complicated by hydrops or changes in amniotic fluid volume
}

\author{
Daphne E Holt, Nicholas M Fisk, John A D Spencer, John de Louvois, Rosalinde Hurley, \\ David Harvey
}

\begin{abstract}
The transplacental transfer of cefuroxime was determined at antenatal fetal blood sampling in a cross sectional study of 78 patients between 15-35 weeks' gestation, 8-138 minutes after a maternal intravenous dose of $750 \mathrm{mg}$. Mean serum cefuroxime concentration, measured by high performance liquid chromatography, was $7 \cdot 4(95 \%$ confidence interval (CI) 6.8 to $8 \cdot 1$ ) $\mathrm{mg} / \mathrm{l}$ in control fetuses; concentrations in hydropic fetuses were similar $(6.2 \mathrm{mg} / 1$, CI $4 \cdot 7$ to $7 \cdot 7)$ but in fetuses with oligohydramnios they were significantly lower, $(4.9 \mathrm{mg} / 1$, CI 3.6 to $6 \cdot 2$ ). Antibiotic concentration did not correlate with gestational age and remained unchanged by transfusion of packed red cells. We conclude that (i) fetal serum concentrations of cefuroxime obtained after a maternal dose of $750 \mathrm{mg}$ are only adequate for prophylaxis against organisms with a minimum inhibitory concentration of $<4 \mathrm{mg} / \mathrm{l}$ and (ii) transplacental passage of cefuroxime is significantly reduced in the presence of oligohydramnios.
\end{abstract}

\section{(Arch Dis Child 1993,68:54-7)}

Infection in utero is implicated as a cause of premature rupture of the membranes and preterm labour. ${ }^{1}$ With the increase in invasive procedures for fetal diagnosis and treatment, and their attendant risk of infection, ${ }^{2}$ there is renewed interest in the placental transfer of antibiotics used for prophylaxis or treatment.

Transplacental antibiotic treatment is based on the premise that a sufficient concentration will reach the intrauterine environment to treat or prevent infection; however there are few data to substantiate this. In several previous studies, concentrations of antibiotic were measured in cord blood at delivery after maternal administration of the antibiotic during labour, ${ }^{34}$ but this approach gives no indication of concentrations attained in fetal serum in utero. Little consideration has been given to the effects on transplacental transfer of such parameters as gestational age, hydrops, abnormal amniotic fluid volume, or procedures such as intravascular transfusion.

Cefuroxime has a broad spectrum bactericidal activity against organisms associated with intrauterine infections. ${ }^{5}$ It is relatively resistant to beta-lactamase degradation, well toler- ated, and free from toxicity, making it suitable for use in pregnancy.

We therefore determined the extent to which a prophylactic dose of maternally administered cefuroxime was transferred to the fetus before antenatal fetal blood sampling in uncomplicated pregnancies and in those complicated by hydrops or abnormalities in amniotic fluid volume. Additionally, we determined the effect of gestational age and intravascular transfusion on the placental transfer of cefuroxime.

\section{Patients and methods}

Mothers undergoing antenatal fetal blood sampling for clinical diagnosis were recruited in this cross sectional study, approved by the local ethics committee. Informed consent for inclusion was given by 78 patients. The concentration of cefuroxime (Zinacef, Glaxo) was determined in fetal serum after a single maternal intravenous dose of $750 \mathrm{mg}$ before antenatal fetal blood sampling at 15-35 weeks' gestation. The general dosage for adults recommended by the manufacturer is $750 \mathrm{mg}$ three times a day. In our hospital a single dose of $750 \mathrm{mg}$ is administered before an invasive procedure when prophylaxis is considered necessary. Ninety six blood samples of volume $1 \mathrm{ml}$ were collected from fetuses at the time of blood sampling for diagnostic or therapeutic indications. Fifteen samples were obtained from normal fetuses undergoing blood sampling for prenatal diagnosis of various conditions from which they were subsequently demonstrated to be unaffected (group 1). Thirty eight fetuses with mild $\mathrm{Rh}$ alloimmunisation were sampled for packed cell volume determination (median 29\%, range $11-48 \%$, group 2), 18 of these underwent intravascular transfusion and a sample after transfusion was obtained. None of the fetuses was hydropic and all had normal amniotic fluid volume on ultrasound. Twenty five fetuses with hydrops or abnormal amniotic fluid volumes were also sampled. Thirteen of these had hydrops and polyhydramnios (deepest vertical pool $>8 \mathrm{~cm}$ ), of which five were associated with alloimmunisation and eight were of non-immune origin (group 3). The other 12 had oligohydramnios (deepest vertical pool $<3 \mathrm{~cm}$ ) associated with obstructive uropathy $(\mathrm{n}=4)$, intrauterine growth retardation $(n=3)$, or renal agenesis $(n=1)$ or it was of idiopathic origin: cystic 
hygroma $(n=2)$, Down's syndrome $(n=1)$, or a cardiac anomaly $(n=1)$ (group 4).

The blood samples were obtained by transabdominal ultrasound guided needling of the umbilical cord at the placental insertion or the intrahepatic vein between eight and 138 minutes after administration of antibiotic to the mother. ${ }^{6}$ The time interval between maternal administration and fetal blood sampling was determined by the particular clinical procedure. Bolus intravascular transfusions of packed red cells were carried out at a rate of $5-15 \mathrm{ml} / \mathrm{min}$. The volume transfused varied between $20-200 \mathrm{ml}$ and the donor packed cell volume between $0 \cdot 65-0 \cdot 80$.

Cefuroxime concentrations were measured by high performance liquid chromatography with a coefficient of variation of less than $4 \%{ }^{7}$ Statistical comparisons were performed with paired and unpaired Student's $t$ tests, while relationships between variables were assessed

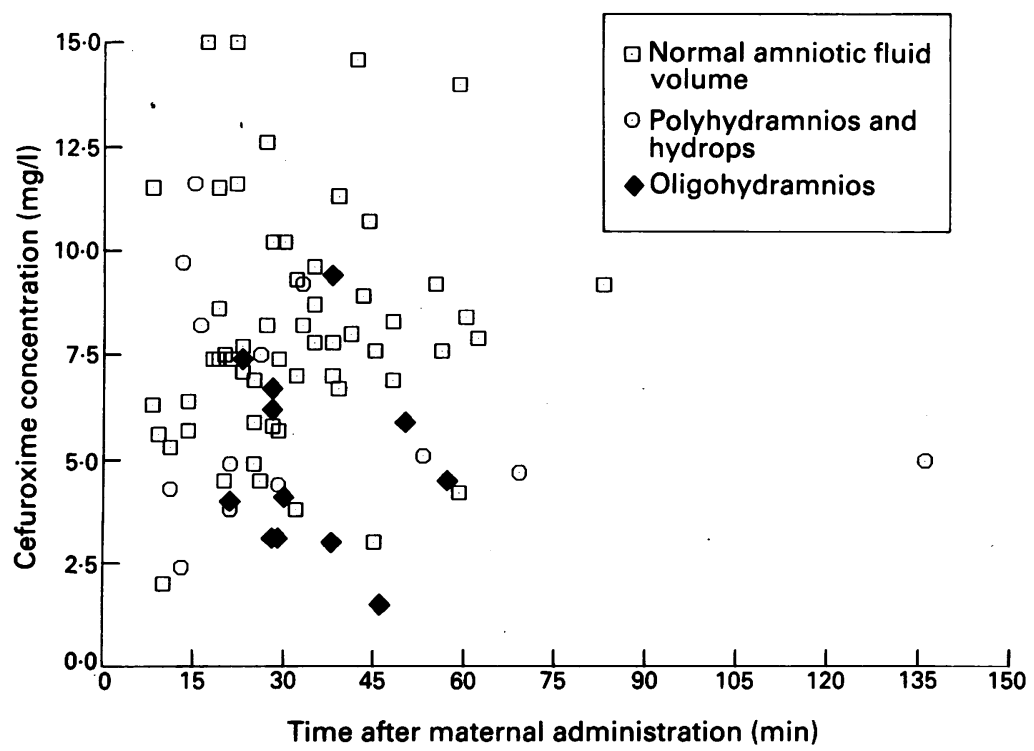

Figure 1 Serum cefuroxime concentrations after a maternal intravenous dose of $750 \mathrm{mg}$ before antenatal fetal blood sampling in fetuses with normal amniotic fluid volume, with polyhydramnios and hydrops, and with oligohydramnios.

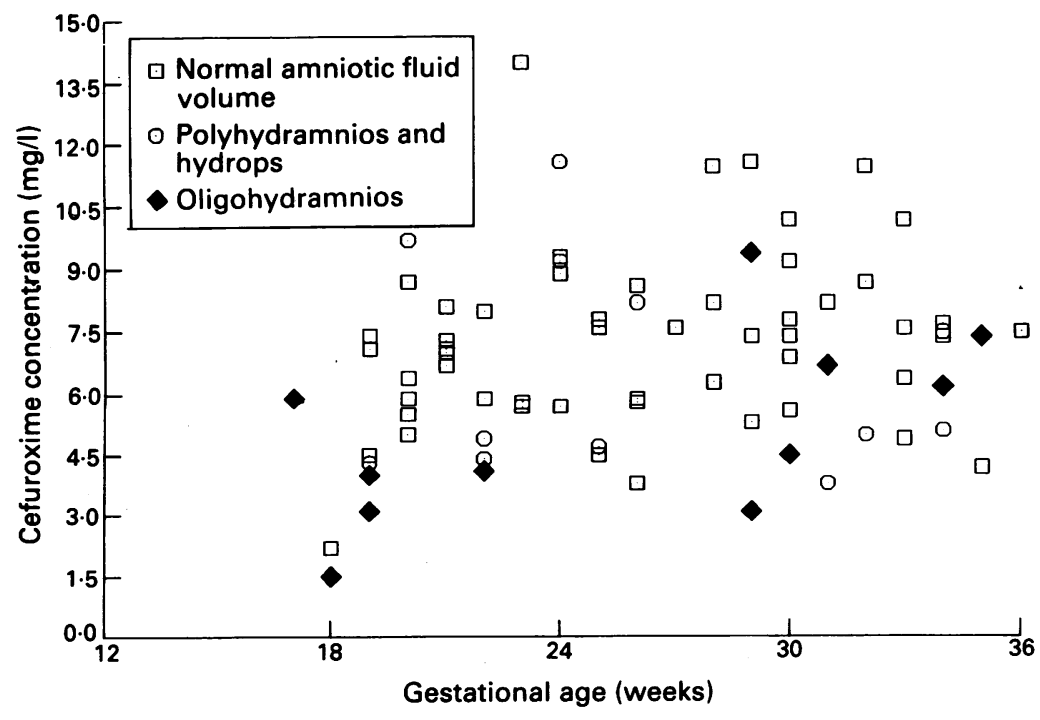

Figure 2 Serum cefuroxime concentrations and gestational age in fetuses with normal amniotic fluid volume, with polyhydramnios and hydrops, and with oligohydramnios. by Pearson's correlation coefficient and linear regression analysis. Logarithmic transformations of the data were performed where necessary to normalise distributions. The data are expressed as geometric mean with $95 \%$ confidence intervals (CI).

\section{Results}

After a maternal intravenous dose of $750 \mathrm{mg}$, cefuroxime was detected in all samples of fetal serum (figs 1 and 2). Serum concentrations were not statistically significantly different in fetuses later assessed as normal (group 1, $\mathrm{n}=15,6.6 \mathrm{mg} / \mathrm{l}, 95 \% \mathrm{CI} 5 \cdot 7$ to $7 \cdot 5 \mathrm{mg} / \mathrm{l})$ and in $\mathrm{Rh}$ fetuses (group 2, $\mathrm{n}=38,7.7 \mathrm{mg} / \mathrm{l}$, CI 6.9 to $8.5 \mathrm{mg} / \mathrm{l}$ ). As none of these fetuses had severe $\mathrm{Rh}$ alloimmunisation, for example none had hydrops or polyhydramnios and their packed cell volumes were above the value normally associated with circulatory changes ${ }^{8}$ and changes in oxygenation, ${ }^{9}$ the two groups were therefore pooled $(n=53,7.4 \mathrm{mg} / \mathrm{l}, \mathrm{CI} 6.8$ to $8.1 \mathrm{mg} / \mathrm{l}$ ) and used as controls for further analysis. In general, fetuses from complicated pregnancies (groups 3 and 4) had lower serum concentrations of cefuroxime than the controls. The mean serum concentration of cefuroxime in those fetuses with polyhydramnios and hydrops (group $3, n=13$ ) was $6 \cdot 2$ $\mathrm{mg} / \mathrm{l}$ (CI 4.7 to $7.7 \mathrm{mg} / \mathrm{l}$ ) and in those with oligohydramnios (group $4, n=12$ ) it was 4.9 $\mathrm{mg} / \mathrm{l}$ (CI 3.6 to $6.2 \mathrm{mg} / \mathrm{l}$ ). However the differences was only statistically significant between the controls and group $4(p=0 \cdot 01)$. In fetuses with hydrops and polyhydramnios, no difference in serum concentrations of cefuroxime was noted between those associated with $R h$ disease compared with those of non-immune origin. Similarly, in fetuses with oligohydramnios there was no difference between those associated with renal dysfunction, intrauterine growth retardation, or those of idiopathic origin. Using linear regression analysis after logarithmic transformation of the data in figs 1 and 2, there was no significant correlation between fetal serum cefuroxime concentrations and either the time from maternal administration to sampling or gestational age in any of the groups.

After intravascular transfusion, fetal serum concentrations of cefuroxime rose or remained unchanged in $14 / 18$ fetuses, with no significant difference between mean concentrations before and after transfusion. No correlation could be demonstrated between the change in concentration and the time between the samples before and after transfusion (fig 3 ), or with gestational age, time after maternal administration, or the volume transfused.

\section{Discussion}

For antibiotic concentrations to be effective for prevention of infection they should either equal or be in excess of the minimum inhibitory concentration (MIC) for potential pathogens. Where the fetus may be infected, adequate concentrations should be achieved in the fetal circulation. Organisms implicated 


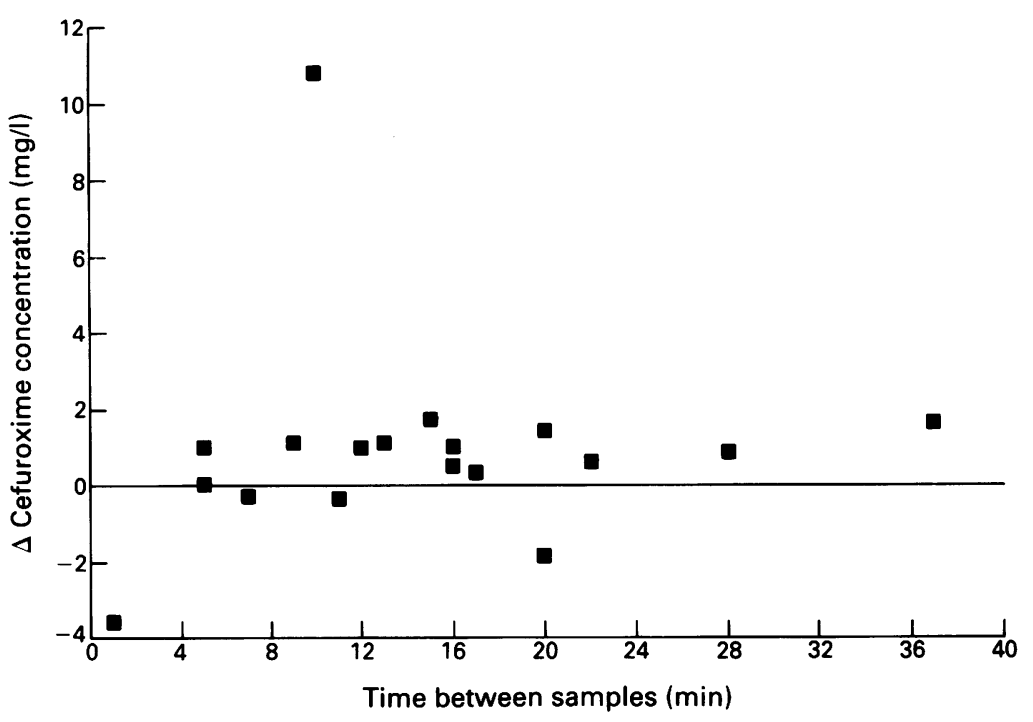

Figure 3 Change in fetal serum cefuroxime concentrations during intravenous transfusion for $R h$ alloimmunisation as a function of procedure duration.

in fetal infection include those isolated from women with postpartum endometritis ${ }^{5}$ (that is, Staphylococcus epidermidis, $\alpha$ and $\beta$ haemolytic streptococci, and anaerobic streptococci) and those from women with acute chorioamnionitis $^{10}$ (that is, group B streptococcus and Escherichia coli). In a study of 67 patients with intra-amniotic infection, ${ }^{10}$ group B streptococci were isolated from $25 \%$ of cases, along with $E$ coli $(21 \%), \alpha$-streptococci $(15 \%)$, and Klebsiella pneumoniae (4\%). In addition Staphylococcus aureus and $\alpha$ haemolytic streptococci have been implicated in fetal infections after cordocentesis and intravascular transfusion. ${ }^{11} 12$ The MIC of cefuroxime for those organisms is generally $<1$ $\mathrm{mg} / \mathrm{l}$. However $20 \%$ of $E$ coli strains, one of the commonest causes of neonatal sepsis, have MICs between 4 and $16 \mathrm{mg} / 1,{ }^{13}$ and only $50 \%$ of klebsiella strains have an MIC <31 mg/1. ${ }^{14}$ While our study demonstrates that cefuroxime crosses the placenta during the second and third trimester to reach concentrations in fetal serum which exceed the MIC for some organisms associated with intrauterine infection, only five fetuses attained serum concentrations of cefuroxime $>12 \mathrm{mg} / \mathrm{l}$. It is therefore likely that higher maternal doses would be required to achieve adequate fetal concentrations against $E$ coli or klebsiella.

In the presence of hydrops with polyhydramnios there was no reduction in the placental transfer of cefuroxime. In contrast, in oligohydramnios, fetal serum concentrations of the antibiotic were significantly reduced. This decrease in cefuroxime transfer may reflect reduced placental function in pregnancies complicated by this condition and suggests that these fetuses may not be adequately protected by a single maternal dose of 750 mg. This could be particularly important in cases of oligohydramnios where amnioinfusion, with its attendant risk of introducing infection, is used for diagnosis and treatment. ${ }^{15}$

The reason for reduced antibiotic transfer in the presence of oligohydramnios remains obscure. Impairment of uteroplacental perfusion in gross polyhydramnios has been suggested, ${ }^{16}$ and may imply a reduction in placental transfer. A reduction in uteroplacental perfusion has also been described in growth retardation, ${ }^{17}$ and therefore a decrease in placental transfer of cefuroxime might be related to reduced blood flow to the placenta. The cause of the abnormality in amniotic fluid volume did not appear to influence placental transfer, although small numbers precluded statistical comparisons between subgroups.

Generally, antibiotics cross the placenta by simple diffusion with the passage dependent upon the ionisation, liquid solubility, protein binding, and molecular weight of the drug. ${ }^{18}$ Protein binding, along with changes in total body water and extracellular water, will also affect distribution in fetal compartments. Cefuroxime was detectable over the entire range of sampling times at virtually constant concentration. Although the time span studied was limited, this may be indicative of a degree of fetal accumulation, as during that time the maternal serum concentrations of the antibiotic decreased exponentially from around $60 \mathrm{mg} / \mathrm{l}$ to $10 \mathrm{mg} / \mathrm{l}$ (DE Holt et al, unpublished data) in accordance with its known pharmacological properties. ${ }^{3}$ In adults cefuroxime is excreted almost entirely by the kidneys. Although the fetal kidney is partly functional by the 12th week of gestation, glomerular filtration rate and tubular function continue to mature well into the third trimester. ${ }^{19}$ The serum half life of cefuroxime is prolonged from 1.5 hours to approximately 20 hours in adult anuric patients. ${ }^{20}$ Thus the apparent accumulation of cefuroxime in the fetus could be due, in part, to reduced renal excretion. Apparent fetal accumulation has been suggested for the first generation cephalosporin cefazolin. ${ }^{21}$ Also, with the third generation cephalosporin ceftizoxime, fetal concentrations are continuously higher than maternal concentrations when a pharmacokinetic steady state is reached. ${ }^{22}$

We were unable to demonstrate a significant relationship between the transplacental passage of cefuroxime and gestational age. Likewise, intravascular transfusion of packed red cells had no effect on fetal serum concentrations of cefuroxime. In these cases equilibrium occurs very quickly, presumably from fetal tissues or the maternal circulation. Most of the volume of fluid transfused during the procedure is rapidly cleared across the placenta, therefore the fetal intravascular volume is likely to remain unchanged. ${ }^{23}$ In neonatal toxicity caused by chloramphenicol, transfusion has only a minimal effect on the serum concentration of the antibiotic. ${ }^{24}$ Multiple exchange transfusions or charcoal haemoperfusion are necessary to reduce antibiotic concentrations. ${ }^{25}$

We have demonstrated that cefuroxime crosses the placenta, unaffected by gestational age or packed red cell transfusion, to achieve a serum concentration in the fetus that is effective against organisms with MICs of $<4 \mathrm{mg} / 1$. Our observation that only around $5 \%$ of fetuses 
attained concentrations $>12 \mathrm{mg} / 1$ that would be reliably effective against organisms with MICs of $4 \mathrm{mg} / \mathrm{l}$ or more, however, suggests that for prophylaxis against some strains of common organisms an increase in dose would be necessary. Fetal serum concentrations of cefuroxime in oligohydramnios are significantly reduced, therefore in these cases a change in regimen might be considered. Further studies are in progress to determine the fetal uptake of an increased dose of cefuroxime.

Dr Fisk was supported by a Joseph Foreman Fellowship from the Royal Prince Alfred Hospital, Sydney, Australia.

The Karim Centre was in receipt of a grant from the Meningitis Trust, Stroud, Gloucester.

1 Minkoff H, Grunebaum AN, Schwarz RH, et al. Risk factors for prematurity and premature rupture of memtors for prematurity and premature rupture of mem-
branes: a prospective study of the vaginal flora in pregbranes: a prospective study of the vaginal flo

2 Berkowitz RL, Chitkara U, Wilkins I, Lynch L, Mehalek KE. Technical aspects of intravascular intrauterine transfusions: lessons learned from thirty three procedures. $\mathrm{Am}$ f Obstet Gynecol 1987;157:4-9.

3 Philipson A, Stiernstedt G. Pharmacokinetics of cefuroxime in pregnancy. Am $\mathcal{f}$ Obstet Gynecol 1982;142:823-8.

4 Bousfield P, Browning AK, Mullinger BM, Elstein M. Cefuroxime: potential use in pregnancy women at term. Brf Obstet Gynaecol 1981;88:146-9.

5 Gibbs RS, Jones PM, Wilder CJ. Antibiotic therapy of endometritis following caesarean section. Obstet Gynecol 1978;52:31-7.

6 Nicolini U, Nicolaidis P, Fisk NM, Tannirandorn Y, Rodeck $\mathrm{CH}$. Fetal blood sampling from the intrahepatic vein: analysis of safety and clinical experience with 214 procedures. Obstet Gynecol 1990;76:47-53.

7 Holt DE, de Louvois J, Hurley R, Harvey D. A high performance liquid chromatography system for the simultaneous assay of some antibodies commonly found in combination in clinical samples. $\mathcal{F}$ Antimicrob Chemother 1990; 26:107-15.

8 Nicolaides $\mathrm{KH}$, Bilardo CM, Campbell S. Prediction of fetal anemia by measurement of the mean blood velocity in the fetal aorta. Am f Obstet Gynecol 1990;162:209-12.

9 Soothill PW, Nicolaides KH, Rodeck CH. Effect of anaemia on fetal acid-base status. Br $\mathcal{F}$ Obstet Gynecol 1987;94:880-3.
10 Yoder PR, Gibbs RS, Blanco JD, Castaneda YS, St Clair PJ. A prospective, controlled study of maternal and perinatal outcome after intra-amniotic infection at term. $A m$ f Obstet Gynecol 1983;145:695-701.

11 Pielet BW, Socol ML, MacGregor SN, Ney JA, Dooley SL. Cordocentesis: an appraisal of risks. Am 7 Obstet Gynecol 1988;159:1497-500.

12 Barss VA, Doubilet PM, St John-Sutton M, Cartier MS, Frigoleto FD. Cardiac output in a fetus with erythroblastosis fetalis: assessment using pulsed Doppler.Obstet Gynecol 1987;70:442-4.

13 Wilkinson PJ, Belohradsky BH, Marget W. A clinical study of cefuroxime in neonates. Proceedings of the Royal Society of Medicine 1977;70(9):183-7.

14 Neu HC, Aswapokee N, Aswapokee P, Fu K. HR 756, a new cephalosporin active against aerobic and anaerobic bacteria. Antimicrob Agents Chemother 1979;15:273-81.

15 Fisk NM, Ronderos-Dumit D, Soliani A, Nicolini U, Vaughan J, Rodeck CH. Diagnostic and therapeutic transabdominal amnioinfusion in oligohydramniosis. Obstet Gynecol 1991;78(2):1-9.

16 Fisk NM, Tannirandorn Y, Nicolini U, Talbert DG, Rodeck $\mathrm{CH}$. Amniotic pressure in disorders of amniotic fluid volume. Obstet Gynecol 1990;76:210-4.

17 Nylund L, Lunell NO, Lewander R, Sarby B. Uterooplacental blood flow index in intrauterine growth retardation of fetal or maternal origin. $\mathrm{Br} f$ Obstet retardation of fetal or

18 Ward RM. Maternal-placental-fetal unit: unique problems of pharmacologic study. Pediatr Clin North Am 1989;36: 1075-88.

19 Nicolini U, Fisk NM, Beecham J, Rodeck CH. Fetal urine biochemistry: an index of renal maturation and dysfunction. Br f Obstet Gynecol 1992;99:46-50.

20 Bundtzen RW, Toothaker RD, Nielson OS, et al. Pharmacokinetics of cefuroxime in normal and impaired renal function: comparison of high-pressure liquid chromatography and microbiological assays. Antimicrob Agents Chemother 1981;19:443-8.

21 Brown CEL, Christmas JT, Bawdon RE. Placental transfer of cefazolin and piperacillin in pregnancies remote from term complicated by $\mathrm{Rh}$ isoimmunization. $A m \mathcal{F}$ Obste Gynecol 1990;163:938-43.

22 Fortunato SJ, Bawdon RE, Welt SI, Swan KF. Steadystate cord and amniotic fluid ceftizoxime levels continuously surpass maternal levels. Am $\mathcal{f}$ Obstet Gynecol 1988;159:570-3

23 Nicolaides $\mathrm{KH}$, Clewell WH, Rodeck $\mathrm{CH}$. Measurement of human fetoplacental blood volume in erythroblastosis fetalis. Am F Obstet Gynecol 1987;157:50-3.

24 Krasinski K, Perkins R, Rutledge J. Grey baby syndrome Revisted. Clin Pediatr (Phila) 1982;21:571-2.

25 Mauer SM, Chavers BM, Kjellstrand CM. Treatment of an infant with severe chloramphenicol intoxication using charcoal-column hemoperfusion. F Pediatr 1980;96:136-9. 